\title{
Catalyst: reimagining sustainability with and through fine art
}

\author{
$\underline{\text { Angela Connelly }}^{1}, \underline{\text { Simon C. Guv }}^{2}, \underline{\text { Dr. Edward Wainwright }}{ }^{3}, \underline{\text { Wolfgang Weileder }}^{4}$ and Marianne Wilde ${ }^{4}$
}

\begin{abstract}
How might we begin to explore the concept of the "sustainable city" in a world often characterized as dynamic, fluid, and contested? Debates about the sustainable city are too often dominated by a technological discourse conducted among professional experts, but this technocratic framing is open to challenge. For some critics, sustainability is a meaningless notion, yet for others its semantic pliability opens up discursive spaces through which to explore interconnections across time, space, and scale. Thus, while enacting sustainability in policy and practice is an arduous task, we can productively ask how cultural imaginations might be stirred and shaken to make sustainability accessible to a wider public who might join the conversation. What role, we ask, can and should the arts play in wider debates about sustainability in the city today? We explore a coproduced artwork in the northeast of England in order to explain how practice-led research methods were put into dialogue with the social sciences to activate new perspectives on the politics, aesthetics, and practices of sustainability. The case is presented to argue that creative material experimentations can be used as an active research inquiry through which ideas can be tested without knowing predefined means or ends. The case shows how such creativity acts as a catalyst to engage a heterogeneous mix of actors in the redefinition of urban spaces, juxtaposing past and present, with the ephemeral and the (seemingly) durable.
\end{abstract}

Key Words: coproduction; interdisciplinarity; practice-led research; sustainability; urban

\section{INTRODUCTION}

We need, in short, to examine the way in which new materialities influence the cultural constructions we place on the environment (Redclift 2005:225).

Action toward resilient and sustainable ways of living has been slow as carbon emissions continue to rise (Folke et al. 2005). It was, after all, only in 2015 that a global action plan to keep emissions reductions below $2^{\circ} \mathrm{C}$ was agreed upon at Conference of Parties (COP) 21 in Paris. We are also urged to adapt to changing climatic conditions and to become more resilient, which implies radical changes to urban forms (Carter et al. 2015). Much of the discussion takes place with a "consensus" that "the environment is best understood and studied as a social-ecological system" and that research should be conducted through the collaboration of a variety of disciplines (Collins et al. 2010).

Even though multidisciplinarity is recognized as crucial in addressing issues related to climate change, long-standing disciplinary divides remain. There are also deep cultural differences and entrenched practices, which mean that transitions to sustainable and resilient futures will be far from smooth and straightforward (Borgstrom et al. 2006, Davoudi 2009). Part of the issue is that ideas such as sustainability, resilience, and climate change are not easily translated from science to policy since language has a cultural dimension (Kagan 2011) and they are contested concepts (Guy 2010, Pelling 2010). Facts and figures are important to the debates but can often fail to win the hearts and minds of people. This has led Bill McKibben, an environmental teacher and activist, to ask, "We can register what is happening with satellites and scientific instruments, but can we register it [climate change] in our imaginations, the most sensitive of all our devices?" (McKibben 2005). Such cultural aspects underscore the need for an arts and humanities perspective to explore and communicate climate change. Engagement with other disciplines may also lead to innovation within science, as it is argued that engagement with a type of creativity that is central to the arts may catalyze scientific insights (Scheffer et al. 2015).

There is a long tradition of artists exploring environmental concerns (Thornes 2008); however, there has been a recent burgeoning of art-science practices that use art to understand how science engages with the wider world and to communicate scientific issues such as climate change (Yusoff and Gabrys 2011, Vervoort et al. 2014). Al Gore's An Inconvenient Truth, for example, did much to popularize climate science through the medium of film in 2006. Meanwhile, art exhibitions have tried to convey complex, scientific ideas; the Arts Catalyst, a UK-based art-science commissioning body, has been in existence for more than 20 years and has sponsored a number of projects that explore ideas around the Global Commons (http://www.artscatalyst. org/). Prior research testifies to the ability of cultural forms to communicate complex scientific ideas (Curtis et al. 2012) and to assist in underpinning environmental planning (Guy et al. 2015).

With respect to climate change, however, "good science + good communication $=$ peace" may be too simplistic, as Mike Hulme (2013:276) observed over the joint award of the 2007 Nobel Peace Prize to the IPCC and Al Gore. As noted, art and culture can be important in shaping responses to climate change. However, when appropriated into other disciplines, art is too often positioned at the end of a process, in order to give legitimation to regeneration projects, for example (Miles 2015). Using art instrumentally to communicate science should, consequently, be approached with caution. Art and art criticism have evolved with internal practices and concerns with respect to appreciation and intent. Moreover, art can be used as a tool to provoke issues. It is a disservice to relegate art to an emasculated role as the communicator of science since art does not just represent the world "as it is"; rather, art can criticize, challenge, and disturb social conventions (Demos 2013).

\footnotetext{
${ }^{1}$ Manchester Architecture Research Centre, The University of Manchester, Manchester, UK, ${ }^{2}$ Faculty of Arts and Social Sciences, Lancaster University, Lancaster, UK, ${ }^{3}$ School of Architecture, Planning \& Landscape, Newcastle University, Newcastle-upon-Tyne, UK, ${ }^{4}$ Fine Art, School of Arts and Cultures, Newcastle University, Newcastle-upon-Tyne, UK
} 
Fig. 1. View of Dunston Staiths, situated on the River Tyne in the northeast of England. (Source: Authors)

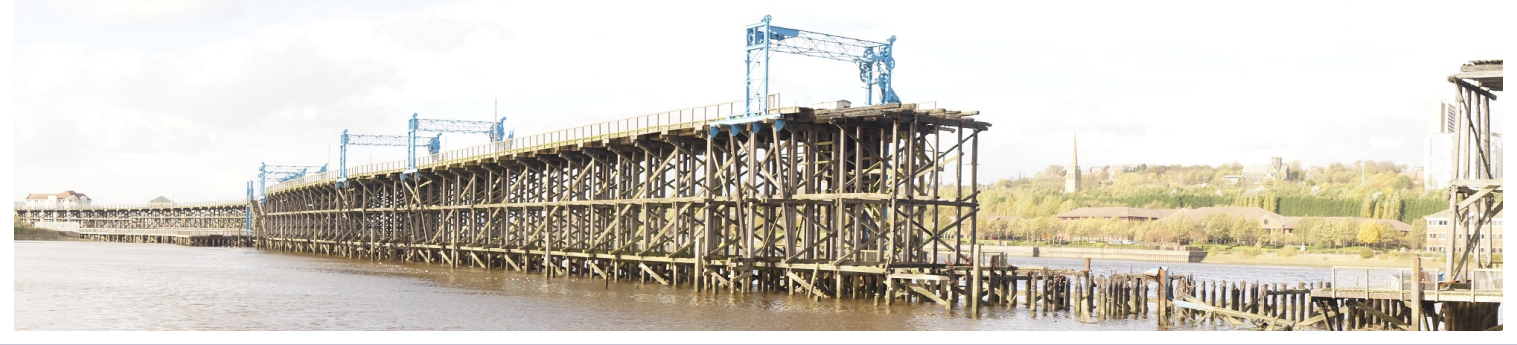

In common with scientists, artists are also often portrayed as creative geniuses, but this viewpoint may hamper working across disciplinary divides. However, art can also be considered to be inherently collaborative. Artists are set within networks of production and consumption that require a whole set of materials and other actors to bring a work of art into being (Becker 1982, Rubio 2012). In some ways, an artist's work is not so far removed from the scientist (de la Fuente 2007, Palsson et al. 2013). There is often a laboratory setting (the "studio") where materials are tested and reworked, and where artistic practice is regarded as a series of experiments with uncertain outcomes.

We intend to show how creative thinking can be harnessed in social-ecological research. We begin from a premise in the design literature that "the best or only way to shed light on a proposition, a principle, a material, a process or a function is to attempt to construct something, or to enact something, calculated to explore, embody or test it" (Archer 1995, as cited in Rust et al. 2007:10). Our main aim was to put fine art practices into productive dialogue with the social sciences, and to show how the methods in fine art may bring prescient insights into social-ecological transformations. We conclude by arguing that incorporating arts and humanities perspectives into projects can refine and develop further research questions (Palsson et al. 2013) as well as create new, shared spaces where different futures (and pasts) can be imagined.

\section{METHODS}

The 15-month "Jetty" project was led by Wolfgang Weileder, a German-born sculptor, who worked in collaboration with fine art researchers and social scientists. The research protocol proceeded with a creative degree of uncertainty: a public artwork would be produced, but there was no fixed idea about the artwork's final form. Jointly constructed research questions explored mutual interests in the deployment of sustainability as an idea, as follows:

- How far can a temporary public artwork act as a catalyst for debates about sustainability and instigate further dialogue between diverse stakeholders?

- What is the range of sustainability concerns mobilized in these debates, and why?

- In what new ways can public art animate community involvement, in advancing or exploring sustainability issues?

- What is the potential legacy and impact of temporary artistic interventions in the context of sustainability?
We used the notion of a "breaching experiment" from ethnomethodology where social conventions are analyzed through staging experiments that contravene established practices -by queue jumping in a society that privileges ordered queues, for example (see Lynch and Peyrot 1992). The Jetty project aimed to disrupt the visual gaze by developing an artwork that responded to a specific site. The intention of such disruptive acts is to "slow down" ongoing processes in order to prompt moments of contemplation that question the otherwise taken for granted (Stengers 2008:40). Disruptive acts can thus allow the space for deeper deliberation in a way that invites many more actors into that reflective space.

The chosen site to explore these questions played to a variety of concerns related to sustainability. Dunston Staiths, located in Gateshead in the northeast of England, is a structure formerly associated with the coal industry (Fig. 1). At $521 \mathrm{~m}$ long, Dunston Staiths, comprised of 98 cross-braced wooden frames, snakes out from the shore into the River Tyne. Coal from the nearby Durham coalfields was transported by rail and off-loaded from Dunston Staiths to moored ships that were berthed on either side of the structure. Dunston Staiths was decommissioned in 1981 following the demise of the UK coal industry but soon became protected by heritage designations. Yet, the structure languished without human use, and nature began to take over (Durham Wildlife Services 2013). A number of protected bird species now roost there during the winter, while the tidal basin has developed into mudflats - a rare habitat in the northeast of England. However, human disuse led to an unexplained fire in 2003 that destroyed $20 \%$ of Dunston Staiths. The resultant gap in the middle of the structure means that the birds now prefer to roost in the isolated eastern end of the site. This is a highly resilient structure, and at the time of the art project, was to be "rescued" with a significant repair grant.

The wider area is interesting in terms of social, environmental, and economic change. Gateshead has been in transition since the early twentieth century, and its history permitted an exploration of gradual social-ecological change. Postindustrial decline in the latter half of the twentieth century led to the need for much social and environmental regeneration. Immediately adjacent to the site, which once housed gasworks and factories, an award-winning sustainable housing development has been in construction since 2006 (IDP Partnership Group 2015). Just beyond the new housing development are areas considered to be in the top $10 \%$ of the most deprived places in England (Gateshead Council 2015). 
To begin, the history of the surrounding areas was investigated. Local and national archives gave an insight into the effects of Dunston Staiths' development and decommissioning on the immediate area. Grey literature and policy documents developed the important strand of Dunston Staiths' conservation and ecological histories. Taken together, the review enabled an identification of stakeholders who were connected to the site over time. Subsequently, interviews (19) and workshops (3) were held among local design and policy professionals as well as residents in the immediate vicinity. The interviews and workshops provided an understanding of how sustainability was imagined in these communities and what their aspirations were for the site in light of the interviewees' memories and experiences. Additionally, conversations between the fine art and the social science team took place on a monthly basis throughout the research activities and were recorded and analyzed along with the interviews and workshops.

\section{RESULTS}

Three proposals emerged from the artist's studio. The first two directly addressed the large gap that had been created in Dunston Staiths following a fire. The intention was to symbolically connect the two sides of the structure to make it, literally, sustainable into the future. The first proposal intended to fill Dunston Staiths' gap with scaffolding, thus acting as a temporary repair to the site and to show the potential of what renewal may imply for the structure. Known as "Bridge", the piece was not built because of practical reasons. The amount of scaffolding needed was estimated at a weight of 140 tonnes, and structural engineers had difficulty surveying the site. With so much uncertainty over Dunston Staiths' properties, there was much caution with regard to what could happen to it.

Timber used in the original construction of the nearby High Level Bridge, designed by George Stephenson, and an iconic structure in northeast England, was found in a timber reclamation yard following restoration on that site. A second proposal, "Gap", intended to recreate the missing gap at a smaller scale and display it in a gallery. The artist, in his studio, worked closely with the timber and drew a number of plans that suggested how the artwork could come to fruition. However, through trial and error, the reclaimed timber was found to possess high mineral oils and potentially heavy metal contamination, which made it too difficult to work with in the allocated time.

Further conversations with the local community suggested that they wanted a large artwork that (aesthetically) played off the scale of the large structure, yet referenced the region's industrial past. In addition, analysis of the interview data and workshops showed that there were various meanings attached to the site; some identified Dunston Staiths as a bird-watching haven, others as a piece of heritage, while many took photographs there. There was an expressed need to connect across the generations by involving schools and children, as well as to reconcile the site's industrial past with a very different future.

In the end, the constructed artwork ("Cone") took the form of a cone, or more precisely, a conical frustum, and was temporarily in place on top of Dunston Staiths for two months (Fig. 2). While a cone is a simple form, in architectural terms, the shape also referenced the nearby brick structures of former industrial glassworks in the area. The artist worked with a material known as Aquadyne (http://www.econoplas.co.uk/aquadyne), which is made from recycled plastics that are often deemed to be unrecyclable and normally go to landfill or incineration (Fig. 3). Aquadyne is typically used in sustainable drainage systems, and can be found in parts of the London 2012 Olympic site, for

Fig. 2. View of Cone on top of Dunston Staiths, August 2014. (Source: Authors)

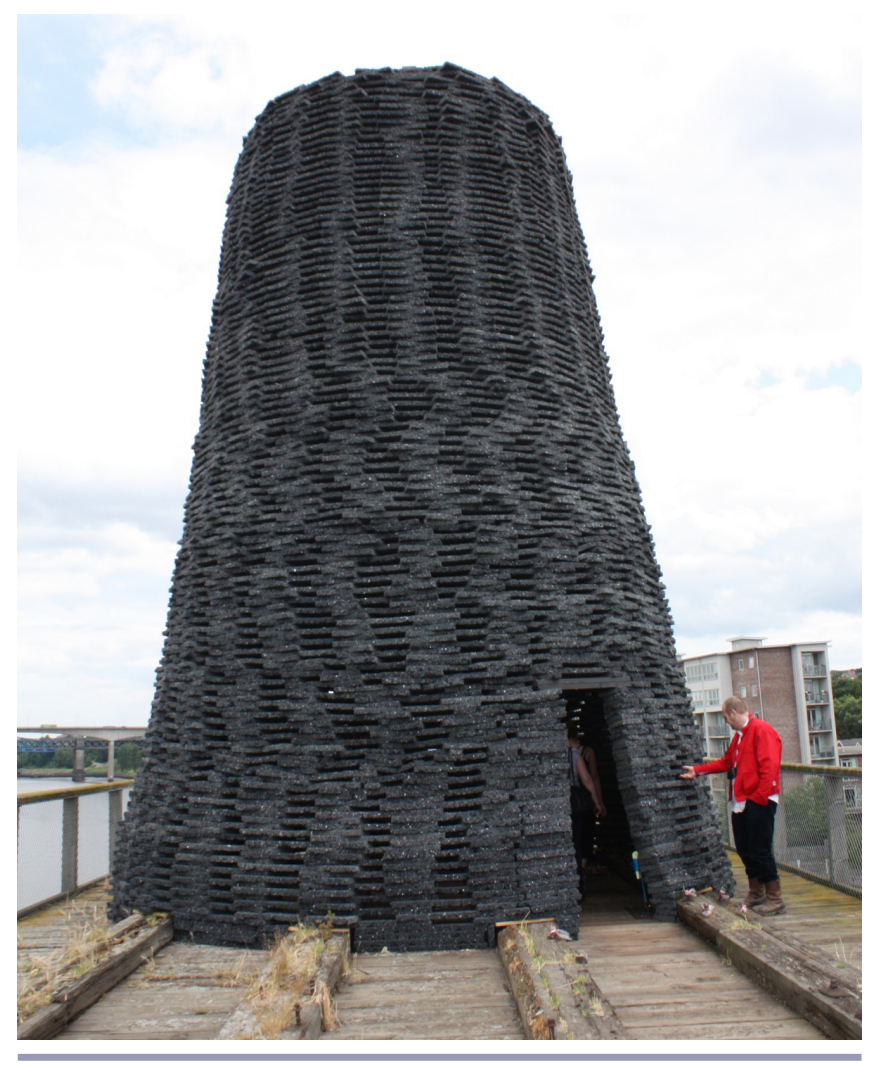

Fig. 3. Close-up shot of Cone showing the composition of Aquadyne, June 2014. (Source: Authors)

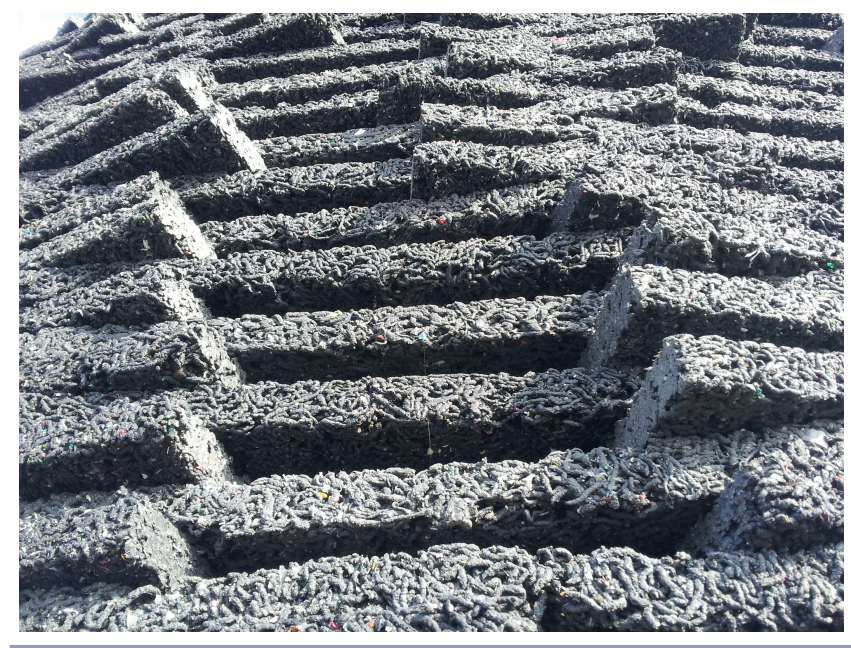


example. It was estimated that the use of Aquadyne embedded the carbon $\left(\mathrm{CO}_{2 \mathrm{e}}\right)$ of 2.1 people in Gateshead. The structure was built by five apprentices from a local further education college, under the direction of the artist, an engineer, and the site manager. The students learned how to work with a new and sustainable material in order to test and understand its resistances and capabilities. One apprentice testified, during construction, that "we normally do building work, not stuff out of recycled products" (Apprentice 3).

Cone's form was incidental; instead, the art piece was a "big marker" in order to draw attention to the site. Cone was deliberately ambiguous in artistic terms and shorn of any symbolism, which made it difficult to appraise aesthetically. Consequently, Cone should be understood as a creative and openended series of events. At $9 \mathrm{~m}$ high by $6 \mathrm{~m}$ wide, Cone was tall enough to provide room for 30 adults and thus provided temporary public space on a structure that was, hitherto, disused. Viewers of the site brought their own readings to the work, meaning that the artwork was not fixed in time: “... looking with it rather than at it, all the while recognising that at any moment in the process of growth, it could have taken a path other than the one actually followed" (Ingold 2013:127).

The artwork also embodied the contested nature of sustainability. Coal, a key contributor to greenhouse gas emissions, once gave Dunston Staiths purpose and meaning. Coal is also crucial to the heritage and collective memory of the northeast of England. Yet the industry has long since vanished and the wider region has struggled to cope with the implications of economic restructuring: "I went over to County Durham the other day and there are wind turbines...there are no pits and [this raises questions of] what do you keep and what do you lose" (Local Resident 5). A range of questions opened up around the transition from one industry to another. The process of making an artwork, therefore, provided a nonspecialist vocabulary to begin to speak with residents about what the site meant to them, and the emotional attachments that they had to the coal industry.

The use of Aquadyne as a material elicited direct responses in line with other artists who have made art out of waste materials (Hawkins 2010). Particularly prominent was the move from recycling to reuse: "What's nice," said one local resident, "is taking waste and reusing it—even temporarily as art...it is something that is often talked about but not necessarily something that you experience so tangibly" (Local Resident 3). This point was further underscored by Cone's temporary duration, which brought into view the continual flux of urban transformations. Ideas such as "entropy" and "uncertainty" were evident through the conversations with residents: "I'm not denying that there is beauty in decay... but at the same time there are... arguments that you just let things grow old gracefully, entropy and all of those kind of ideas" (Local Resident 2).

Nature and culture rub up together on the site. At a microlevel, the negotiations involved in balancing various concerns came into view. Like many similar "ruins", Dunston Staiths is not preserved in aspic but continually changes in ways that may be unnoticeable to the naked eye. However, the literal question of how to sustain became wrapped up in economic considerations which supersede deep social, environmental, and cultural concerns (While 2007). Ecological professionals tried to emphasize balance, but this revealed the ongoing tensions between human understandings of nature: "I think that it is important to say that we all have an interest in it [Dunston Staiths]. If you just left it you would have nothing... and fundamentally that would be a loss in ecological terms and in heritage terms" (Ecological Professional 1). Since Cone was the first major intervention onto the site in the years since Dunston Staiths had closed, such remarks hinted at the delicate balancing act that is required to address competing sustainability concerns.

Dunston Staiths is obsolete, and like other obsolete pieces of architecture, it resists attempts to reimagine a different future. The response to the artwork brought out the various tensions involved during times of change and transformation but the real need to strike a balance. Since competing concerns needed to be accommodated, we will never know what the birds would have made of Cone, for example. Local planners decided that the artwork had to be dismantled before the birds returned to Dunston Staiths for their roosting period. Since the deconstruction of the artwork, some of the Aquadyne has found its way into a Northumbrian Wildlife Trust building, which further emphasizes the circular processes at work and that the city and its component parts do not operate in a linear fashion.

\section{DISCUSSION}

Ensuring that the research was plausible was a shared notion through which both disciplines operated. This referred to internal plausibility among the project team, and external plausibility to ensure that the research was credible among the range of audiences that the project engaged with. This can be seen in a conversation among the project team (Text Box 1).

\section{Box 1:}

Artist: I think it is important that you follow a clear methodology; although intuition plays a big role in our making...I guess with all research, intuition plays a big role.... So plausibility for me is very important, in terms of what identifies good research, in terms of fine art practice. So you can understand why the result is as it is, or where it is coming from.

Social scientist: So the plausibility, it is almost like you...you materialize the hypothesis through the work? And you test the plausibility through that?

Artist: Yes, but...I am not illustrating any ideas, so the research is basically to test things out and make things...I test them out in the models and so on, and then develop a visual language and develop a product... but the journey...needs to be plausible, it needs to be understandable why I made certain decisions along the way.

The notion of intuition, as opposed to planned decision-making, may be considered as "tacit knowledge" and is holistic in approach (Hogarth 2010). Intuition is closely associated with creation and invention: "Intuition is, of all things in the world, the rarest, but most equally distributed among inventors - be they artists or scientists" (Michael Serres quoted in Serres and Latour 1995:99). 
While the arts and sciences may share different premises, with art being open-ended, while science leads to closed insights, there is nevertheless "a turbulent river of shared intuitions about the order and disorder of things" (Kemp 2005:309). Thus, in interdisciplinary work, there needs to be attentiveness to the concept of intuition in order to garner it for productive use. The notion of research plausibility (as opposed to testability) was the means of operationalizing intuition in the Jetty project.

By using intuition as a basis, new questions opened up and the visual breaching experiment provided more ideas and insights. Of critical importance was understanding how the two disciplines interacted with one another. The social science research, for example, enabled a focus on what place means within a wider community. Collective memory and the idea of place in narratives of transformation was an important theme during the research. Questions were raised regarding the pace and intention of (sustainable) urban development patterns, the role of heritage, and what might be gained and lost, socially and culturally, by changing developmental and clean industrial patterns. The demise of the coal industry, for example, was marked by juxtaposing a green technology-Aquadyne-against the decaying structure of Dunston Staiths in order to emphasize such transitions.

The two unrealized proposals, Bridge and Gap, were equally important. Design thinking notes that success occurs through failure (Petroski 2008). Failure becomes part of the natural cycle from which an end-product emerges, and the process holds useful insights. In the Jetty project, such testing of materials was used to push the boundaries of what could happen on site and shaped the eventual form of the artwork. It also prompted the site owners, and others, to enter into a dialogue about how change could be made possible and what form it took by allowing limited numbers of people onto the site. Consequently, small-scale testing of what might happen can be used to explore the boundaries of the unknown - an observation that is applicable across a number of domains.

The temporary artwork provided a shared space to explore what urban sustainability might mean in practice in one small area. In part, Cone helped gather momentum around the preservation and future use of the site: the funding for the art project was used as match funding in a wider heritage funding bid. At a conceptual level, the process of making Cone also hinted at the need for careful interpretations. Experiences related to spirituality, heritage, and identity are important in shaping humanenvironment relationships, but are often overlooked (Gould et al. 2014). The conversations that took place among the Jetty project team hinged largely around how to translate different perspectives into something collectively meaningful. How do we, for example, present the history of coal and greenhouse gas emissions in a way that neither unduly lauds the achievements nor laments its demise? This opened up a further set of questions around the social and cultural implications of transition and change - in what ways does this affect the collective memories inherent in local places? Such "backward" looking questions were the most prevalent uncovered during the research, yet they are often missing in terms of the broader debates around moving toward resilient social-ecological systems.

\section{CONCLUSION}

We present a site-specific, coproduced artwork to explain how art can be put into productive dialogue with the social sciences to activate new perspectives on the politics, aesthetics, and practices of sustainability. Art, we argue, can be used as a creative inquiry through which ideas can be tested without knowing predefined means or ends. The artistic approach helped concretize an idea such as sustainability, which too often appears to be an abstract concept, when speaking with local residents and other stakeholders.

The overall project, however, was not only about communication but also demonstrated the way in which art can shape research activities and develop areas of further inquiry. Social scientists typically establish and answer research questions. The engagement with fine art enabled those questions to be refined in order to go deeper into the experience of social-ecological transformations. The production of the artwork also suspended preconceived ideas. In this way, a richer dialogue opened up between the community and the researchers to shed a light on questions that are often not tackled within contemporary environmental research. Of particular importance was the drawing out of emotional responses to environmental change: what does it really mean when one industry is lost to be replaced, perhaps, by another? How can emotional and cultural attachments best be explored and given voice to? What new pathways open up, and above all, are we fully aware of what might be lost in the transition toward more sustainable and resilient cities?

From the artistic point of view, the social science element contributed to the design of the artwork through the ability to foreground the complex networks of stakeholders and communities. In addition, the social science dialogue emphasized the artwork as a catalyst and not an interpretation, visualization, or final statement that forms part of the art world (Guy 2015). New perspectives were opened up for the fine art team around undertaking site analysis and means of speaking with local communities. In this way, it is the making of the artwork, rather than the artwork itself, in which the synergies and dialogues are cocreated. Instead of closing discussions down, the fine art project enabled new questions to be formed and provided a tool through which to bring a wider audience into examining the complexity of social-ecological transformations.

Responses to this article can be read online at: http://www.ecologyandsociety.org/issues/responses. $\mathrm{php} / 8717$

\section{Acknowledgments:}

This research was funded by the Arts and Humanities Research Council (UK) as "The Jetty Project" ( $\underline{\text { http://www.jettv-project. }}$ info) with the grant reference: AH/K006932/1. The authors want to thank their partners in the project, including the Tyne and Wear Building Preservation Trust, particularly Martin Hulse and Kari Vickers, Gateshead College, the Mears Group, rBAU Ltd, Layher, 
and Taylor Wimpey for their time and material contributions to the project. Additionally, the authors wish to thank the anonymous reviewers whose comments improved an earlier draft of the paper.

\section{LITERATURE CITED}

Becker, H. S. 1982. Art worlds. University of California Press, Berkeley, Los Angeles, London.

Borgstrom, S. T., T. Elmqvist, P. Angelstam, and C. AlfsenNorodom. 2006. Scale mismatches in management of urban landscapes. Ecology and Society 11(2):16. http://www. ecologyandsociety.org/vol11/iss2/art16/

Carter, J. G., G. Cavan, A. Connelly, S. Guy, J. Handley, and A. Kazmierczak. 2015. Climate change and the city: building capacity for urban adaptation. Progress in Planning 95:1-66. http://dx.doi.org/10.1016/j.progress.2013.08.001

Collins, S. L., S. R. Carpenter, S. M. Swinton, D. E. Orenstein, D. L. Childers, T. L. Gragson, N. B. Grimm, J. M. Grove, S. L. Harlan, J. P. Kaye, A. K. Knapp, G. P. Kofinas, J. J. Magnuson, W. H. McDowell, J. M. Melack, L. A. Ogden, G. P. Robertson, M. D. Smith, and A. C. Whitmer. 2010. An integrated conceptual framework for long-term social-ecological research. Frontiers in Ecology and the Environment 9:351-357. http://dx.doi. org/10.1890/100068

Curtis, D. J., N. Reid, and G. Ballard. 2012. Communicating ecology through art: what scientists think. Ecology and Society 17(2):3. http://dx.doi.org/10.5751/ES-04670-170203

Davoudi, S. 2009. Scalar tensions in the governance of waste: the resilience of state spatial Keynesianism. Journal of Environmental Planning and Management 52:137-156. http://dx.doi. org/10.1080/09640560802666495

De la Fuente, E. 2007. The 'new sociology of art': putting art back into social science approaches to the arts. Cultural Sociology 1:409-425. http://dx.doi.org/10.1177/1749975507084601

Demos, T. 2013. Contemporary art and the politics of ecology. Third Text 27:1-9. http://dx.doi.org/10.1080/09528822.2013.753187

Durham Wildlife Services. 2013. Dunston Staiths: ecological enhancement and wildlife plan. [online] URL: http://dwsecology. co.uk/dunston-staithes/

Folke, C., T. Hahn, P. Olsson, and J. Norberg. 2005. Adaptive governance of social-ecological systems. Annual Review of Environmental Resources 30:441-473. http://dx.doi.org/10.1146/ annurev.energy.30.050504.144511

Gateshead Council. 2015. Indices of deprivation 2015 - briefing for Gateshead. [online] URL: http://www.gateshead.gov.uk/ People\%20and \%20Living/StatisticsandCensus/IMD.aspx

Gould, R. K., N. M. Ardoin, U. Woodside, T. Satterfield, N. Hannahs, and G. C. Daily. 2014. The forest has a story: cultural ecosystem services in Kona, Hawaii. Ecology and Society 19(3):55. http://dx.doi.org/10.5751/ES-06893-190355

Guy, S. 2010. Pragmatic ecologies: situating sustainable building. Architectural Science Review 53:21-28. http://dx.doi.org/10.3763/ $\underline{\text { asre. } 2009.0102}$
Guy, S. editor. 2015. Catalyst: art, sustainability and place in the work of Wolfgang Weileder. Kerber, Bielefield, Germany.

Guy, S., V. Henshaw, and O. Heidrich. 2015. Climate change, adaptation and eco-art in Singapore. Journal of Environmental Planning and Management 58:39-54. http://dx.doi. org/10.1080/09640568.2013.839446

Hawkins, H. 2010. Turn your trash into...rubbish, art and politics. Richard Wentworth's geographical imagination. Social and Cultural Geography 11:805-827. http://dx.doi.org/10.1080/14649365.2010.522719

Hogarth, R. M. 2010. Educating intuition. University of Chicago Press, Chicago, Illinois, USA.

Hulme, M. 2013. Exploring climate change through science and in society: an anthology of Mike Hulme's essays, interviews and speeches. Routledge, Abingdon, UK.

IDP Partnership Group. 2015. Staiths South Bank: a retrospective. IDP Partnership Group, Newcastle. [online] URL: https://www.gateshead.gov.uk/DocumentLibrary/Leisure/ CountrysideWildlife/countryside/Staiths-Retrospective.pdf

Ingold, T. 2013. Making: anthropology, archaeology, art and architecture. Routledge, Abingdon, UK.

Kagan, S. 2011. Art and sustainability: connecting patterns for a culture of complexity. Transaction Publishers, New York and London.

Kemp, M. 2005. From science in art to the art of science. Nature 434:308-309.

Lynch, M., and M. Peyrot. 1992. Introduction: a reader's guide to ethnomethodology. Qualitative Sociology 15:113-122. http:// dx.doi.org/10.1007/BF00989490

McKibben, B. 2005. What the warming world needs now is art, sweet art. Grist Magazine, April $22^{\text {nd }}$. [online] URL: http://grist. org/article/mckibben-imaginel

Miles, M. 2015. Limits to culture: urban regeneration vs. dissident art. Pluto Press, London, UK.

Palsson, G., B. Szerszynski, S. Sörlin, J. Marks, B. Avril, C. Crumley, H. Hackmann, P. Holm, J. Ingram, A. Kirman, M. P. Buendía, and R. Weehuizen. 2013. Reconceptualizing the "Anthropos" in the Anthropocene: integrating the social sciences and humanities in global environmental change research. Environmental Science \& Policy 28:3-13. http://dx.doi. org/10.1016/j.envsci.2012.11.004

Pelling, M. 2010. Adaptation to climate change: from resilience to transformation. Routledge, London; New York, USA.

Petroski, H. 2008. Success through failure: the paradox of design. Princeton University Press, Princeton, New Jersey, USA.

Redclift, M. 2005. Sustainable development (1987-2005): an oxymoron comes of age. Sustainable Development 13:212-227. http://dx.doi.org/10.1002/sd.281

Rubio, F. D. 2012. The material production of the spiral jetty: a study of culture in the making. Cultural Sociology 6:143-161. http://dx.doi.org/10.1177/1749975512440226 
Rust, C., J. Mottram, and J. Till. 2007. Practice-led research in art, design and architecture. AHRC Research Review, Swindon, UK. [online] URL: http://arts.brighton.ac.uk/_data/assets/pdf file/0018/43065/ Practice-Led_Review_Nov07.pdf

Scheffer, M., J. Bascompte, T. K. Bjordam, S. R. Carpenter, L. B. Clarke, C. Folke, P. Marquet, N. Mazzeo, M. Meerhoff, O. Sala, and F. R. Westley. 2015. Dual thinking for scientists. Ecology and Society 20(2):3. http://dx.doi.org/10.5751/ES-07434-200203

Serres, M., and B. Latour. 1995. Conversations on science, culture, and time: Michel Serres interviewed by Bruno Latour. University of Michigan Press, Ann Arbor, Michigan, USA.

Stengers, I. 2008. Experimenting with refrains: subjectivity and the challenge of escaping modern dualism. Subjectivity 22:38-59. http://dx.doi.org/10.1057/sub.2008.6

Thornes, J. E. 2008. A rough guide to environmental art. Annual Review of Environmental Resources 33:391-411. http://dx.doi. org/10.1146/annurev.environ.31.042605.134920

Vervoort, J. M., D. H. Keuskamp, K. Kok, R. van Lammeren, T. Stolk, T. A. Veldkamp, J. Rekveld, R. Schelfhout, B. Teklenburg, A. Cavalheiro Borges, S. Jánokóva, W. Wits, N. Assmann, E. Abdi Dezfouli, K. Cunningham, B. Nordeman, and H. Rowlands. 2014. A sense of change: media designers and artists communicating about complexity in social-ecological systems. Ecology and Society 19(3):10. http://dx.doi.org/10.5751/ES-06613-190310

While, A. 2007. The state and the controversial demands of cultural built heritage: modernism, dirty concrete, and postwar listing in England. Environment and Planning B 34:645-663. http://dx.doi.org/10.1068/b32085

Yusoff, K., and J. Gabrys. 2011. Climate change and the imagination. Wiley Interdisciplinary Reviews: Climate Change 2:516-534. http://dx.doi.org/10.1002/wcc.117 